\title{
Inovação em saúde mental sob a ótica de usuários de um movimento comunitário no nordeste do Brasil
}

\author{
Innovation in mental health from the perspective of users: \\ a community movement in the Northeast of Brazil
}

\begin{abstract}
Maria Lúcia Magalhães Bosi ${ }^{1}$
Liliane Brandão Carvalho

Veronica Morais Ximenes ${ }^{3}$

Anna Karynne da Silva Melo ${ }^{2}$

Maria Gabriela Curubeto Godoy ${ }^{1}$
\end{abstract}

\footnotetext{
${ }^{1}$ Laboratório de Avaliação e Pesquisa Qualitativa em Saúde, Faculdade de Medicina, Departamento de Saúde Comunitária, Universidade Federal do Ceará. Rua Prof. Costa Mendes $1608 / 5^{\circ}$, Rodolfo Teófilo. 60430-140 Fortaleza CE. malubosi@ufc.br ${ }^{2}$ Centro de Ciências Humanas, Universidade de Fortaleza

${ }^{3}$ Departamento de Psicologia, Centro de Humanidades, Universidade Federal do Ceará
}

\begin{abstract}
This study, originating from a multidimensional analysis on the innovation category in a Community Mental Health Movement of Bom Jardim (Fortaleza, Brazil) that examines subjective and psychosocial dimensions, seeks to examine to what extent the work developed by this movement is effectively an innovative model in mental healthcare from the perspective of users of this service. The methodology adopted was a qualitative case study method based on a critical-interpretive approach employing techniques such as in-depth interviews associated with focus groups. The categorization of the discursive material was conducted using a model based on the four main dimensions of psychiatric reform, namely conceptual, technical, legal and socio-cultural aspects. The results reveal the following: an emphasis on the individual rather than focusing on the sickness; care as the basis for purposeful actions; the co-production of genuine dialogue with multiple stakeholders, and the construction of autonomy emphasizing individual potential. In conclusion, it can be said that healthcare practices developed by the Movement involve deconstructing the traditional model of mental healthcare, permitting new forms of citizenship, thereby contributing to deinstitutionalization.
\end{abstract}

Key words Innovation, Mental health, Deinstitutionalization
Resumo Este estudo, oriundo da análise multidimensional sobre a categoria inovação no Movimento de Saúde Mental Comunitária do Bom Jardim (Fortaleza), cuja proposta é trabalhar dimensões subjetivas e psicossociais, objetiva interrogar se e como as experiências desenvolvidas se constituem efetivamente como práticas de cuidado inovadoras em saúde mental, na perspectiva dos usuários desse dispositivo. O percurso metodológico delineou-se na abordagem qualitativa, na modalidade estudo de caso, em uma vertente críticointerpretativa, empregando como técnicas, entrevistas em profundidade associadas a grupos focais. A categorização analítica das informações foi construída a partir de um modelo fundado nas dimensões constituintes da Reforma Psiquiátrica, abrangendo distintos planos: epistemológico, assistencial, jurídico-politica e sociocultural. Os resultados revelam: ênfase no sujeito social doente, não mais na doença; acolhimento como fundamento propositivo das ações; co-produção de diálogos genuinos com múltiplos atores envolvidos; e construção da autonomia e fortalecimento do poder pessoal. Tais elementos evidenciam que as práticas de cuidado tecidas no cotidiano do Movimento implicam desconstrução com o modelo tradicional de atenção à saúde mental, potencializando novas formas de cidadania, desse modo, contribuindo para a desinstitucionalização.

Palavras-chave Inovação, Saúde mental, Desintitucionalização, Práticas de cuidado 


\section{Introdução}

Este estudo se originou na pesquisa Práticas Inovadoras e Desinstitucionalização: Analisando um Movimento Comunitário em Saúde Mental no Nordeste do Brasil que abrange uma análise multidimensional da categoria inovação em saúde mental focalizando um movimento comunitário - o Movimento de Saúde Mental Comunitária do Bom Jardim (MSMCBJ ou Movimento). Nosso propósito foi interrogar se e como as experiências em curso no Movimento constituem efetivamente práticas de cuidado inovadoras em saúde mental, na perspectiva dos usuários desse dispositivo. O MSMCBJ realiza suas ações predominantemente na região do Grande Bom Jardim, periferia de Fortaleza, e tem como proposta enfrentar o desafio de trabalhar com dimensões subjetivas e psicossociais, valorizando as pessoas que chegam em situação de sofrimento, oferecendolhes diferentes modalidades de cuidado. Suas atividades são organizadas em cinco eixos: Terapêutico; Educativo; Arte, Música, Espetáculo e Cultura; Profissionalizante; e Formação. Neste estudo, focalizamos as atividades do Eixo Terapêutico, constituído pelas atividades de Terapia Comunitária, Massoterapia, Autoestima e Biodança.

Sabemos que o processo em curso da Reforma Psiquiátrica brasileira e seus avanços demandam a construção de novos modos de estar diante da pessoa em adoecimento, instituindo no campo da saúde mental práticas inovadoras de desinstitucionalização e de inclusão social que se materializam em uma rede de cuidados centrada no território. Tal avanço demanda, assim, a realização de estudos que abordem experiências consideradas efetivas na construção de redes psicossociais e de novas práticas em saúde mental.

É justamente nesse escopo investigativo que se insere a presente proposta. Tal empreendimento se justificou, tendo em vista a visibilidade nacional e internacional do Movimento, dentre outros indícios de que o mesmo vem operacionalizando um modelo diferenciado, afetando a vida de quem nele participa, no sentido de promover melhorias em várias esferas da existência dessas pessoas, propiciando seu empoderamento na busca por mudanças pessoais e sociais. Contudo, até o presente momento essa experiência não se encontra(va) sistematizada, nem tampouco avaliada com base em pressupostos e procedimentos pautados pelo rigor científico, constituindo assim uma lacuna na literatura.

Dado que a dimensão do cuidado se constitui como valor, ou seja, um bem simbólico circulante a partir do qual emergem novas relações e vínculos, justifica-se uma análise desta experiência, em uma perspectiva multidimensional, privilegiando aqui a visão dos usuários - ainda que parte de um estudo mais amplo que inclui outros atores, de maneira a contribuir com novas reflexões para o campo da saúde mental na direção de novos modelos que possam subsidiar a reforma em curso.

\section{Reforma Psiquiátrica e desinstitucionalização: uma compreensão de inovação em saúde mental}

O processo da Reforma Psiquiátrica contribuiu para a implementação de uma nova política pública de assistência de saúde mental e para a construção de tecnologias de cuidado inovadoras $^{1}$. Pauta-se na ideia de desinstitucionalização, a qual pode ser compreendida como desospitalização - prevenção das internações nos hospitais psiquiátricos; desassistência - ausência de assistência orientada pelo modelo tradicional; e desconstrução - ruptura com o paradigma da loucura e com o saber médico que reduz o sujeito à doençą ${ }^{2}$.

Demarcaremos então a perspectiva de $d e$ sinstitucionalização como desconstrução tal como proposto por Amarante ${ }^{3,4}$, exigindo não apenas um novo lugar para a loucura e o desmonte dos "aparatos científicos, legislativos e administrativos"5 que configuram o paradigma psiquiátrico, mas também uma nova relação com a alteridade.

Consoante tais proposições, optamos por operacionalizar um modelo analítico estruturado nas dimensões da Reforma Psiquiátrica, assinaladas por Amarante ${ }^{6}$ entendendo que tal modelo mostra-se oportuno tanto para o campo da Reforma Psiquiátrica, como, sobretudo, para pensarmos outras perspectivas de cuidado à saúde mental. Passemos, pois, à definição de cada uma das esferas: teórico-conceitual; técnico-assistencial; jurídico-política e sociocultural.

A dimensão epistemológica diz respeito à revisão dos conceitos que embasam o saber/fazer de cada perspectiva, bem como à produção de outras formas de conhecimento. A assistencial refere-se às questões do modelo de atenção e cuidado, dos dispositivos, equipamentos e ferramentas técnicas propostos para responder às demandas no campo da saúde mental. A jurídico-política traz à tona discussões relativas à cidadania e aos direitos civis, sociais e humanos, assim como à criação de legislações próprias a esse campo. Por fim, a sociocultural vincula-se ao lugar reservado às pessoas em sofrimento psíqui- 
co, o que inclui considerar estigmas e preconceitos da mesma forma que estratégias e intervenções que possibilitem uma nova forma de relação com a loucura, ou seja, novos lugares.

Tradicionalmente, o termo inovação circula mais fortemente em outros campos, em especial em estudos administrativos e organizacionais, como fator determinante do desenvolvimento e da sustentabilidade das instituições empresariais, enquanto lócus de competitividade. Nesse escopo, inovação é o processo de introduzir novos conhecimentos na criação e na otimização de produtos, significando também, mudanças nos processos produtivos e de gestão ${ }^{7}$.

No campo da saúde, especificamente na biotecnologia, a inovação descreve a primeira utilização de um novo procedimento em um paciente que necessita de uma nova solução para um problema clínico ${ }^{8}$. Hockfield ${ }^{9}$ assinala a convergência de saberes que tem possibilitado os avanços nas ciências da vida. Inovar requer assim uma formação mais ampla dos pesquisadores e profissionais, o que implica interdisciplinaridade.

Em uma pesquisa sobre o significado de inovação nas intervenções de profissionais da saúde pública na Inglaterra, foram elencadas características de intervenções inovadoras, tais como: uma intervenção diferente para modelos já estabelecidos; algo que pode ser aplicável em toda a população; uma intervenção já existente utilizada de forma diferente; algo que reduz a desigualdade ${ }^{10}$.

Para além de questões relacionadas às esferas produtiva e tecnológica, as mudanças ocorridas no campo da saúde mental que visam a superação ou a ruptura com o modelo asilar e manicomial, centrado no controle da doença, trazem em seu bojo a inovação enquanto um desafio de transformação do saber e do fazer dos profissionais e demais atores envolvidos. Inovação, em uma leitura para além da técnica, implica também produção de conhecimento potencializador do desenvolvimento dos próprios recursos dos sujeitos envolvidos. Inovar em saúde (coletiva) obriga, assim, a buscar possibilidades de recursos e de novas formas de gestão das políticas públicas de saúde, gerando fortalecimento de processos no desenvolvimento de serviços e práticas em contextos presentes ou futuros. Pensar inovação remete, portanto, ao entrelaçamento com outras questões importantes para o campo da saúde, tais como a governabilidade e a participação cidadã ${ }^{11}$.

A urgência, portanto, é de um novo ethos, uma nova atitude diante da experiência da pessoa em sofrimento psíquico, pautada por res- ponsabilidade, inventividade, respeito, escuta, afetação, diálogo e compromisso ético-politico possibilitadores da construção de passagens para a autonomia.

Desse modo, neste estudo, compreendemos inovação fundamentalmente como processo; um movimento de mudança que potencializa novos modos de interação, saberes e práticas, promotor de desalojamentos e, consequentemente, de necessários tensionamentos. Enquanto movimento, sua marca é de experimentação, no sentido de criação, de desconstrução e, sobretudo, de produção de novos modos de cuidado na saúde mental que impliquem novas formas de cidadania ${ }^{12}$.

\section{Método}

Dada a natureza do objeto, o percurso metodológico se voltou para a produção subjetiva dos sujeitos implicados, o que levou à adoção da abordagem qualitativa. Frente os diferentes desenhos metodológicos de investigação social qualitativa, optamos pelo estudo de caso, o qual oportuniza a construção de conhecimentos abrangentes e de aprofundamentos a partir da singularidade de um caso $^{13}$.

Assim, mediante um desenho compreensivo e descritivo, intencionamos, conforme antes aludido, compreender as experiências que vêm sendo implementadas por um movimento comunitário no âmbito da Saúde Mental, em um contexto social específico e sob a ótica dos usuários, constituindo-o como caso, ou seja, como experiência singular que interfaceia a Rede de Saúde Mental do município de Fortaleza, embora sem nela se inserir formalmente.

Criado em 1996, o MSMCBJ, caracteriza-se por ser uma organização não-governamental (ONG) que figura juridicamente como associação comunitária, realizando ações que integram a saúde mental, a arte, a cultura, a educação e a profissionalização em âmbito local. Historicamente, o MSMCBJ é herdeiro da tradição das Comunidades Eclesiais de Base (CEBs) e da atuação de missionários Combonianos.

Quanto às vertentes, ante à diversidade que caracteriza a tradição qualitativa, este estudo se alinhou à tradição crítico-interpretativa, na perspectiva da hermenêutica filosófica de Hans-Georg Gadamer ${ }^{14}$. Tomamos a subjetividade na interface com a materialidade a que se vincula, na qual consciência e mundo se unificam no ato compreensivo, sem uma orientação linear ou preponderância de um plano sobre o outro. Compreender 
enquanto condição hermenêutica primária "não é compreender melhor, nem saber mais, no sentido objetivo, em virtude de conceitos mais claros [...] Bastaria dizer que, quando se logra compreender, compreende-se de um modo diferente" 14 .

Quanto aos informantes, buscamos os usuários das práticas nucleares, considerando-os atores propiciadores do desvelamento do fenômeno investigado, em uma perspectiva dialógica, esclarecendo que, tendo em vista o modelo de cuidado do Movimento, muitos desses usuários circulam por diversas atividades do Eixo Terapeutico.

A amostra, composta de 20 usuários (entrevista individual ou grupo focal), foi, portanto, de tipo teórica, ou seja, os informantes foram escolhidos não por sua representatividade estatística, mas sim pela sua relevância para a questão da pesquisa, ou seja, o acúmulo subjetivo que se vincula ao objeto e ao marco teórico subjacente à pesquisa ${ }^{15}$. O tamanho da amostra foi delineado pelo principio da saturação teórica, segundo o qual as as informações fornecidas pelos novos participantes da pesquisa pouco acrescentariam ao material já obtido, não mais contribuindo significativamente para o aperfeiçoamento da reflexão teórica ${ }^{16}$.

Em termos mais específicos e consoante os princípios éticos adotados, seguindo os procedimentos da Resolução 196/ CNS, no termo aprovado pelo Comitê de Ética em Pesquisa da Universidade Federal do Ceará, os critérios de inserção dos usuários participantes foram: tempo mínimo de 06 meses frequentando o Movimento, cabendo ressalvar que toda aproximação temporal tende a ser arbitrária; idade mínima de 18 anos para responsabilizar-se pelos depoimentos; condições psíquicas e físicas de prestar informações sobre atendimentos anteriores; e anuência ao estudo após ciência do termo de consentimento e demais informações sobre a pesquisa. Os usuários foram entrevistados por 02 pesquisadores da equipe, na sede do Movimento, em entrevista individual ou grupo focal a partir de uma pergunta disparadora, desdobrada segundo o principio da não-diretividade, consoante as categorias e os temas que se mostravam relevantes ao longo do processo

\section{Resultados e discussão}

\section{Uma inovação em saúde mental? \\ O Movimento na ótica dos usuários}

A partir do exposto, apresentamos as informações obtidas junto aos usuários, categorizadas segundo cada uma das quatro dimensões constituintes da Reforma ${ }^{6}$, tal como antes detalhadas.

Na dimensão epistemólogica, temos a reconfiguração do objeto de intervenção, cuja finalidade não é mais a mera remissão dos sintomas, mas as necessidades de saúde propriamente humanas. Nas falas dos usuários, revela-se que a ênfase não incide na doença e sim no sujeito social ou "pessoa" doente. As pessoas vêm para cá, inclusive eu vim, assim geralmente [com] uma depressão, alguma dificuldade, digamos assim, nem transtorno, alguma dificuldade. (E1). Aqui a gente se sente mais à vontade porque tem pessoas assim iguais à gente; aí não tem a gente chegar acorrentado não e lá [hospital] tem. (E3)

Reconhece-se a necessidade de transformar o saber e o fazer dos profissionais, o que significa a organização de novas bases teóricas e praticas de condução dos projetos assistenciais e a invenção de novos modos de produzir saúde ${ }^{17}$. Essa dimensão é também marcada pela produção de saberes, transformação e diversificação de respostas $^{18}$. Essa essência é nossa que a gente sabe fazer muito bem: o acolher, o respeitar, o valorizar a vida. (E4) Um local onde você vai pra dividir, dividir os problemas e ouvir também as pessoas. (E5)

Tais perspectivas são reveladas quando se traça um paralelo entre o antes e o depois da chegada ao Movimento e tem-se tanto a percepção da diferença como dos impactos em sua vida. Eu me vejo outra pessoa; antes de eu chegar aqui eu vivia com uma forte depressão; hoje eu me sinto capaz, eu sou capaz, eu me acho importante, vejo sentido na minha vida. [Saúde mental é] A busca da saúde [que] você esteja precisando; é a saúde da mente; é uma mente cansada, assim, esgotada com o dia a dia e as correrias da vida e aqui você encontra saúde. (E7) Saúde mental é estar bem, eu entender qual é o universo em que eu estou, eu entender que moro lá no Bom Jardim e que não faz vergonha eu dizer que moro no Bom Jardim; é eu me aceitar do jeito que eu sou. (E1) 
Os usuários descrevem a questão existencial do sofrimento, que podemos entender como outra característica da dimensão teórico-conceitual. Afirmam não haver uma centralização no transtorno e que o sofrimento reconhecido vai além do sofrimento psíquico, considerando o contexto de pobreza e de abandono ${ }^{19}$. A pobreza não somente unidimensional, no aspecto monetário, e sim multidimensional, que engloba saúde, educação e padrão de vida ${ }^{20}$. A cara do Movimento é esse acolhimento mesmo; esse acolhimento sem distinção de raça, de cor, de credo, mas esse acolhimento e assim sem perder de vista a profissionalização, a tecnologia. (GF1) Sempre o lema daqui, do jeito de tratar as pessoas, a maneira como as pessoas falam, como as pessoas te atendem, enfim, eu acho que o próprio clima, o próprio ambiente já te acolhe. (E5)

Consoante os depoimentos, evidenciam-se rupturas com o discurso hegemônico na saúde e com a racionalidade médica moderna ${ }^{21}$. Graças a Deus que eu tive essa depressão porque até então eu achava assim que eu não vivia, que eu não me conhecia, que eu não tinha força e quando veio essa depressão veio pro meu bem. Hoje em dia eu me conheço mais, eu aprendi a me ver através dessas terapias, a saber o que eu quero da vida. (E8)

A dimensão do acolhimento surge nas falas como fundamento propositivo das ações do Movimento como um serviço que dá suporte às diferenças. O Movimento é o Movimento em movimento, que acolhe, recebe, trata, que para um pouco pra escutar a gente; por mais apressados que nós estejamos. (E4) Ainda nessa primeira dimensão, foram reveladas questões como oportunidades e profissionalização das pessoas da comunidade e apontados os desafios organizacionais do Movimento a partir da ampliação das atividades. Têm pessoas que realmente vestem a camisa do Movimento e têm outras que não vestem. Têm outras que tão tentando aprender, conviver, vestir devagarinho, porque às vezes a gente exige logo que a pessoa vista e às vezes o processo élento e têm pessoas que precisam ser ajudadas. (GF1) Os problemas que estão surgindo agora que são desafios, e não são problemas que vem para acabar com o Movimento, mas para melhorar, é a questão mesmo da organização interna, da profissionalização das pessoas. [É necessária uma] visão um pouco mais técnica sem perder o lado humano. (E6)

A segunda dimensão - assistencial - é revelada nos depoimentos dos usuários como: relações pautadas por respeito e acolhimento, e menos pela anulação da diferença e mera aplicação de técnicas; aproximação, presença e disponibilidade da equipe; reconhecimento das necessidades dos usuários, bem como pela produção de diálogos com múltiplos atores: os usuários e sua rede relacional - familiares, vizinhos e pessoas do território $^{18}$. Acolher é a partir do momento que entra no serviço, primeiramente tu tens que te acolher; primeiramente, acho que nós temos que nos acolher $e$ depois acolher o outro. Acho que acolhimento não é por classe, tem que ser igual pra qualquer pessoa. (E4) Aqui acolheram o meu choro, acolheram a minha tristeza, a minha dor. (E8) Não te perguntam nada, não querem saber nada da tua vida, querem é procurar te ajudar de alguma forma [marca peculiar desse acolhimento], te livrar daquele problema ali, daquela situação. (E1) É ter muita paciência e muita sensibilidade e assim essa abertura mesmo, gostar, estar disponivel pra essa história da doação, da solidariedade. (E5) A diferença éo atendimento, como você é atendida. Todos dizem bomdia, pegam na minha mão, conversam, eles ouvem; ouvir, desabafar é a diferença. (E10)

Processo, interatividade, inclusão de novos atores e o conceito de rede refletem as dinâmicas interativas e envolvem as múltiplas e contínuas conexões entre os diversos atores ou esferas. Os profissionais demoram com você. (E2) O Movimento me fez realmente entender o sentido mesmo da vida. (E4) Ali [grupo de autoestima] você interage com outros jovens, é como se abrisse portas pra você poder ver, como abrissem mundos diferentes, o meu caso foi assim. (E11)

É necessário pensar uma política de inovação alicerçada na dimensão social, para além do lócus da competitividade, a busca é por uma maior e melhor distribuição dos resultados, direcionando-os para necessidades ou problemas sociais mais abrangentes ${ }^{22,23}$. E a dimensão social é delineada ainda pela questão do cuidado como atitude ética: Ninguém sabe da minha doença, ninguém entende, aí meus momentos ruins mesmo é lá que eu passo, é lá que eu choro, é lá que eu me consolo; lá, dentro na terapia. E agora estou fazendo aquele [grupo de] autoestima também, porque lá eu tenho tudo de bom; não tem assim porque a gente é doente [...] não tem assim uma diferença do bom pro doente. (E3)

$\mathrm{Na}$ reabilitação psicossocial, a implicação maior é a desconstrução de práticas fundadas na objetivação da doença mental e a (re) construção de práticas voltadas para as necessidades expressas pelas pessoas ${ }^{17}$. Tal desconstrução pautada por uma atitude ética também se revela nas falas: A terapia, o que ela me traz é isso, essa oportunidade de falar e de ouvir e de perceber também o mundo, de perceber que todo mundo tem problema e a gente vai também, vai através dessa escuta 
e dessa fala, desse desabafo; a gente vai encontrando os caminhos. [Quanto à questão do cuidado com o cuidador] $O$ pessoal daqui tem muita formação, eles também são cuidados, eu acho que é isso assim, pra que isso aconteça, eles também são acolhidos, eles também têm a formação. (E5)

Nas falas dos entrevistados ressalta-se a terapia comunitária ${ }^{24}$ como espaço propiciador de acolhimento diferenciado: $\mathrm{Na}$ terapia comunitária a gente desabafa como a gente tá e a gente vê muita gente assim pior do que a gente lá; e a gente melhora. (E3)

Mandato social e papel dos técnicos na rede substitutiva e territorial ${ }^{18}$ também se revelam nas falas de dois entrevistados. Digo que o Movimento não me deixou sentir nem dor direito, porque eu fui tão bem acolhida, tão bem tratada que a partir dai tive esse olhar, esse cuidado mesmo, e a partir daí, eu senti a necessidade que eu também poderia estar ajudando. (E4) Olha, aqui no movimento é o tipo de ajuda, de terapia que vai além de simplesmente falar alguma coisa no consultório, ouvir alguma coisa. Aqui é uma terapia onde eu estou arregaçando as mangas e pondo em prática, vai com certeza me ajudar a, pouco a pouco, voltar ao ritmo de vida, de trabalho, de estudo que eu desejo viver. (E6)

Tais depoimentos ressoam na reorganização do processo de trabalho e no serviço centrado nas necessidades dos usuários ${ }^{25}$, bem como numa ação participativa e de responsabilidade de diversos atores $^{21}$ que permite que os envolvidos na coordenação sejam também usuários, cujas percepções se expressam em falas como a que segue: Tenho certe$z a$ que a gente faz porque a gente gosta e eu acho que é por isso que nós somos motivados. O Movimento é muito sábio quando se coloca as equipes nos seus locais certos; tem algo a mais e nós do Movimento a gente não trabalha em prol só do dinheiro, de dizer assim: eu trabalho porque eu sei no final do mês eu tenho meu dinheiro garantido, não! Tem algo maior que nos motiva: essa coisa mesmo do acolher, de tá lidando mesmo com seres, com pessoas. (E4)

Em relação à experimentação, à invenção, à criatividade e ao afeto ${ }^{26}$; encontros, tensões e maior capacidade dialógica, aguçando a capacidade de pactuação $0^{27}$, são conceitos entrelaçados a práticas inovadoras. Hoje é que a gente vê aqui na terapia que tem essa troca de dar e receber e também, eu acho que eu cheguei à terapia porque eu acabei dando mais do que eu podia, às vezes você se doa demais e não percebe que esquece um pouco de você. (E5) Um momento da escuta, quando a gente escuta que acolhe a dor do outro eu me senti assim com um apoio maior, uma força maior [...]; o grupo de biodança, expressão corporal, tra- balha o corpo e a mente, ás vezes eu chegava com o meu corpo cansado sem força pra respirar bem; eu aprendi a lidar a respiração. (E7)

A valorização de atividades que tecem a vida cotidiana, a atuação no território, fomentando o fortalecimento de redes de apoio e a integralidade do cuidado ${ }^{2}$ também são aspectos apontados pelos entrevistados: Não tive nem tempo assim de cair totalmente; eu digo que o Movimento botou uma rede e me acolheu antes d'eu cair. (E4) Assim, se você pode tratar, tratar mais com produtos naturais, com coisas naturais ao invés de ficar só tomando remédio, então acho que poderia, uma das coisas, era incentivar mais essa coisa da farmácia viva, da alimentação mais saudável. (E5)

Um aspecto presente ainda nessa dimensão técnico-assistencial é a do voluntariado como função terapêutica vinculada ao projeto de vida. $O$ bom do Movimento é que todos nós aqui nos conhecemos mesmo, a gente sabe onde é que tá cada profissional, onde é que mora, o nome, o que faz. Eu acho que cada dia aqui no Movimento, cada dia que você chega, você é motivada a algo mais. (E4)

Contudo, um aspecto revelado foi a fragilidade das atividades voluntárias e suas descontinuidades expressas como: curador ferido, negligência do autocuidado, desejos de manicômio ${ }^{28}$, normatização do cuidador e ampliação do Movimento. Tais elementos constituem ameaças à sustentabilidade do modelo atualmente em curso, sugerindo a necessidade de monitoramento e de um seguimento atento ao que ora se passa, sobretudo em um cenário de ampliação e de entrada de novos atores, tal como revela uma usuária que hoje também atua como cuidadora: É um preconceito muito grande ainda hoje com a pessoa que é funcionário e que passou por um momento de crise antes de entrar no Movimento, então eu sinto essa diferença com determinadas pessoas. Hoje o Movimento cresceu e vivemos na correria mesmo, sua hora marcada de atendimento de pacientes $e$ não sobra um pouco de tempo assim pra você conversar, pra você juntar aquela turma todinha e fazer essa vivência e a gente sente falta (GF 2)

A terceira dimensão jurídico-politica envolve: reabilitação, tomada de responsabilidade, estabelecimento de relações, maior cidadania, autonomia e poder contratual ${ }^{17}$, bem como produção de direitos ${ }^{18}$. A história da aceitação de si e do outro, às vezes a gente vive querendo mudar os outros e a gente não consegue mudar nem a gente mesmo. (E5) Devo muito isso, essa decisão de sair daqui, de enfrentar realmente, de trabalhar em casa com minhas irmãs, de estar de porta em porta mesmo, de trabalhar com massagem. (E1) 
A compreensão e a construção de passagens para a autonomia ${ }^{26}$; valor pessoal e poder pesso$\mathrm{al}^{29}$; fragilização da autoestima; superação da dependência e do fatalismo ${ }^{30}$; e fortalecimento ${ }^{31}$ foram descritos pelos usuários nesta terceira dimensão. Você não veio pra sofrer, você veio pra ser feliz, claro que o sofrimento faz parte do crescimento, mas você sofre, você trabalha aquele sofrimento e vai pra frente. (E5) Era pequenininha não como pessoa, mas assim como mulher eu era pequenininha e agora não, eu, a dona J. (E12)

O que me deixa felizé saber que eu tenho uma vida livre pra eu escolher o que eu quero, eu tenho livre arbitrio de escolher, eu sei agora; me conscientizo do que é bom e do que é ruim pra mim e nada vai me abalar mais. (E7)

Outra questão que emergiu nos depoimentos é a liderança altruísta, cujo "exercício da direção das tarefas comunitárias vai além do bom cumprimento, excede o esperado e o exigido, passando a construir o que se considera como um estado superior de ética, quer dizer, a consideração e o respeito do Outro representado não só pelo coletivo da comunidade senão pelo ser humano"31. ${ }^{\prime}$ uma coisa humanizada, é uma coisa que você sai daqui nas alturas assim, você, essa coisa da fé, mas a fé que não te prende, que te liberta. (E5) Ainda sonho com isso, que vai chegar o momento de o Movimento de Saúde Mental não só ser reconhecido por reconhecido, mas o poder público também estar junto fazendo parcerias maiores. (E4)

A última dimensão, sociocultural, corresponde à produção de políticas públicas locais e intersetoriais, bem como por redes e serviços substitutivos e territoriais que visam a superação do modelo asilar, o voluntariado e a flexibilidade de papéis. Vejo o trabalho voluntário como uma articulação de vida, assim: é um doar um pouco de você no qual você lá pode conhecer pessoas que mais na frente podem te ajudar e você ser fraterno com o outro. (E7) É a coisa do dar e do receber, nós damos, mas nós recebemos e eu acho que esse receber é que nos motiva a estar. (E4)

A invenção de um novo lugar social para a experiência do adoecimento é constitutiva dessa quarta dimensão. Desse modo, ressaltamos a importância de o serviço de saúde mental ficar permanentemente atento ao risco de não reproduzir uma prática asilar no seu cotidiano e que o discurso não se situe apenas no plano discursivo, mas, sobretudo, em projetos de um modo mais humanizado de cuidado. O povo acha que é mentira e isso é o mesmo que dar uma facada na gente. Se chegar um e disser: não, isso aí não é verdade não, pronto; isso aí ta derrotando a gente.
(E3) Hoje me chamo V. porque o Movimento me fez conhecer meu bairro, o Movimento me fez entender realmente como é o Bom Jardim, como é bom morar no Bom Jardim. Quando tu vai conhecer, tu começa a se fortalecer e dizer: eu também faço parte dessa realidade aqui, eu não posso fugir $e$ isso fez eu olhar com outro olhar, outro cuidado comigo e com o outro. (E4)

A partir das dimensões privilegiadas, podemos apontar que as atividades do eixo terapêutico, como a terapia comunitária, a massoterapia, os grupos de autoestima e a de biodança, sob a ótica aqui revelada pelos usuários, sugerem a presença de inovação na prática de cuidado. Práticas estas que se caracterizam pela invenção de novos modos de produção de saúde mental e se constituem privilegiadamente por: cuidado enquanto atitude ética, marcado, sobretudo, por uma ênfase no acolhimento, no ouvir, no respeito, na presença, na dialogicidade e nas necessidades do outro - o usuário; o sentido do valor pessoal e ressignificação da própria sintomatologia; voluntariado e oportunidade de profissionalização; cidadania e por uma atuação no território. Tal como sintetizam as seguintes falas: é um local onde você vai pra dividir, dividir os problemas e ouvir também as pessoas [...] enfim, eu acho que é o próprio clima, o próprio ambiente já te acolhe né, um ambiente agradável de se estar e o jeito como elas te atendem (E5); quero que esse Movimento seja a cada dia esse local de acolhimento que as pessoas cheguem [...] que passe pro Movimento, que tenha esse prazer, que tenha essa estrutura, essa base porque eu acho que passar no Movimento você já sai outra pessoa com um olhar maior e primeiramente cuidando de você e sabendo que você é capaz e que você está aqui também pra conquistar. (E1)

\section{Considerações Finais}

As práticas de cuidado do Movimento, comprometidas com o processo de transformação pessoal e coletivo, visam o estímulo da autonomia e do empoderamento das pessoas e dos grupos na busca da transformação da realidade local. Nesse sentido, e sob a ótica dos usuários informantes desta pesquisa, podemos assegurar que as práticas de cuidado tecidas no cotidiano dessa experiência, longe de intencionar ou restringir-se a fazer uma apologia ao caso investigado, implicam desconstrução ou rupturas com o modelo tradicional de atenção em saúde mental, promovendo necessários tensionamentos. 
Ao longo deste trabalho compreensivo, o Movimento revelou como marca privilegiada a experimentação, no sentido de criação, a construção de passagens e a produção de novos modos de cuidado a pessoas em situação de sofrimento. Novos modos que se materializam em práticas de cuidado menos excludentes e no reconhecimento dos determinantes bio-psico-sócio-culturais do adoecimento, em que saúde passa a ser considerada como processo no qual o sujeito se atualiza no mundo, construindo e atribuindo significados às experiências.

Empreender inovação em um serviço de saúde mental é concretizá-lo enquanto espaço de encontro genuíno, acolhimento, afetação, não anulação da diferença, autonomia, criatividade, reflexividade e, sobretudo, produção de novas formas de cidadania ${ }^{12}$, cuja exigência é por transformações concretas imediatas e locais de emancipação e transformação do cotidiano, aqui e agora, para além da mera concessão de direitos e deveres. A produção de um novo modo de cuidado, sustentado pela circularidade do dar, receber, retribuir, constitui-se como desafio nodal à potencialização dessa nova cidadania em todos os atores envolvidos - seja o usuário, o cuidador, o familiar e a comunidade entendidos como partes de uma rede que opera em conjunto.

\section{Colaboradores}

MLM Bosi, LB Carvalho e AKS Melo participaram na elaboração da metodologia, obtenção e análise do material discursivo, redação do esboço inicial e final do artigo; VM Ximenes participou na elaboração da metodologia, fundamentação e redação final do artigo; e, MGC Godoy participou na elaboração da metodologia e em parte do trabalho de campo.

\section{Agradecimentos}

A equipe agradece o apoio financeiro recebido do CNPq e à FUNCAP - Fundação Cearense de Apoio ao Desenvolvimento Cientifico e Tecnológico - pelo auxilio. Agradecemos ainda à coordenação do Movimento e aos usuários participantes desta pesquisa pelo apoio ao desenvolvimento do estudo e pelos depoimentos que nos foram confiados. 


\section{Referências}

1. Silva MBB. Responsabilidade e Reforma psiquiátrica brasileira: sobre a relação entre saberes e políticas no campo as saúde mental. Rev Latino-americana de psicopatologia fundamental 2005; 8(2):303-321.

2. Godoy MGC, Bosi MLM. A alteridade no discurso da Reforma Psiquiátrica Brasileira face à Ética Radical de Lévinas. Physis 2007; 17(2):289-299.

3. Amarante $\mathrm{P}$, organizador. O homem e a serpente: outras histórias para a loucura e a psiquiatria. Rio de Janeiro: Fiocruz; 1996.

4. Amarante P. Loucos pela vida: a trajetória da reforma psiquiátrica no Brasil. Rio de Janeiro: Fiocruz; 1998.

5. Rotelli F, Leonardis O, Mauri D. Desinstitucionalização. São Paulo: Hucitec; 1990.

6. Amarante P. A Clínica e a Reforma Psiquiátrica. In: Amarante P, organizador. Archivos de Saúde Mental e Atenção Psicossocial. Rio de Janeiro: Nau editora; 2003.

7. Cerezo JAL. Los entornos de la innovación. Revista CTS 2004; 1(2):189-193.

8. Lanzafame RJ. Responsibilities and Innovation. Photomed Laser Surg. 2010; 28(1):1-2.

9. Hockfield S. The Next Innovation Revolution. Science 2009; 323(5918):1147.

10. Fung M, Simpson S, Packer C. Identification of innovation in public health. J Public Health 2011; 33(1):123-130.

11. León AR. Gobernabilidad, Innovación Y Participación Ciudadana em Salud: columna vertebral de La política em salud. Salud em Tabasco 2003; 9(1):197-199.

12. Santos B de S. Pela mão de Alice: o social e o político na pós-modernidade. 13a ed. São Paulo: Cortez; 2010.

13. Yin RK. Estudo de caso: planejamento e métodos. Porto Alegre: Bookman; 2001.

14. Gadamer H-G. Verdade e Método. Petrópolis: Vozes; 1997.

15. Schwandt TA. The Sage Dicitionary of Qualitative Inquiry. New York: Sage Publications; 2007.

16. Fontanella BJB, Ricas J, Turato ER. Amostragem por saturação em pesquisas qualitativas em saúde: contribuições teóricas. Cad Saude Publica 2008; 24(1):17-27

17. Barros OMAF, Silva ALA. Práticas Inovadoras para o cuidado em saúde. Rev Esc Enferm 2007; 41(N. Esp):815-819.

18. Nicácio F, Campos GWS. A complexidade da atenção. Rev. Ter. Ocup. 2004; 15(2):71-81.
19. Drew, N, Funk M, Tang S, Lamichhane J, Chávez E, Katontoka S, Pathare S, Lewis O, Gostin L, Saraceno $\mathrm{B}$. Human rights violations of people with mental and psychosocial disabilities: an unresolved global crisis. Lancet 2011; 378(9803):1664-1675.

20. Sen A. Desenvolvimento como liberdade. São Paulo: Companhia das Letras; 2000.

21. Pinheiro R, Guizardi FL. Cuidado e integralidade: por uma genealogia de saberes e práticas no cotidiano. In: Pinheiro R, Mattos RA, organizadores. Cuidado: as fronteiras da integralidade. $2^{a}$ edição. Rio de Janeiro: Cepesc,Uerj,Abrasco; 2005. p. 21-36.

22. Conde MVF, Araújo-Jorge TC. Modelos e concepções de inovação: a transição de paradigmas, a reforma da C\&T brasileira e as concepções de gestores de uma instituição pública de pesquisa em saúde. Cien Saude Colet 2003; 8(3):727-741.

23. Novella EJ. Mental health care and the politics of inclusion: A social systems account of psychiatric deinstitutionalization. Theor Med Bioeth 2010; 31(6):411-427.

24. Barreto AP. Terapia Comunitária passo a passo. Fortaleza: Gráfica LCR; 2005.

25. Franco TB. Produção do cuidado e produção pedagógica: integração de cenários do sistema de saúde no Brasil. Interface Comun Saúde Educ 2007; 11(23):427-438.

26. Castro ED, Lima EMF. A. Resistência, inovação e clínica no pensar e no agir de Nise da Silveira. Interface Comun Saúde Educ 2007; 11(22):365-376.

27. Franco TB, Merhy EE. Atenção domiciliar na saúde suplementar: dispositivo da reestruturação produtiva. Cien Saude Colet 2008; 13(5):1511-1520.

28. Machado LD, Lavrador MCC. Loucura e Subjetividade. In: Machado LD, Lavrador MCC, Barros MEB de, organizadores. Texturas da psicologia: subjetividade e política no contemporâneo. São Paulo: Casa do Psicólogo; 2007.

29. Góis CWL. Noções de Psicologia Comunitária. Fortaleza: Editora Viver; 1993.

30. Martín-Baró I. Psicología de la liberación. Madrid: Trotta; 1998.

31. Montero M. Teoria e Práctica de la Psicologia Comunitária. Buenos Aires: Editorial Paidós; 2003.

Apresentado em 10/11/2011

Aprovado em 01/12/2011

Versão final apresentada em 06/12/2011 